Article

\title{
Postharvest Losses and their Determinants: A Challenge to Creating a Sustainable Cooking Banana Value Chain in Uganda
}

\author{
Enoch Mutebi Kikulwe $^{1, *(\mathbb{D})}$, Stanslus Okurut ${ }^{2}$, Susan Ajambo ${ }^{1}{ }^{(\mathbb{D}}$, Kephas Nowakunda ${ }^{3}$, \\ Dietmar Stoian ${ }^{4}$ and Diego Naziri ${ }^{5,6}$ (D) \\ 1 Bioversity International, Susan Ajambo Bioversity, P. O. Box 24384 Kampala, Uganda; s.ajambo@cgiar.org \\ 2 School of Agricultural Sciences, Makerere University, P. O. Box 7062 Kampala, Uganda; \\ stanslusokurut@yahoo.com \\ 3 National Agricultural Research Laboratories of the National Agricultural Research Organization (NARO), \\ P. O. Box 7065 Kampala, Uganda; nowakunda@gmail.com \\ 4 Bioversity International, Parc Scientifique Agropolis II, 34397 Montpellier, France; d.stoian@cgiar.org \\ 5 International Potato Center (CIP), 100000 Hanoi, Vietnam; d.naziri@cgiar.org \\ 6 Natural Resources Institute (NRI), University of Greenwich, Chatham ME4 4TB, UK \\ * Correspondence: e.kikulwe@cgiar.org; Tel.: +256-393-216-526
}

Received: 24 May 2018; Accepted: 3 July 2018; Published: 9 July 2018

check for updates

\begin{abstract}
Postharvest losses (PHL) result in direct food and income losses to farmers and consumers globally. PHL reduction strategies offer unique opportunities to contribute to sustainable food systems for increased food security and farm incomes for more than 200 million food insecure people in sub-Saharan Africa. Lack of empirical information remains a major challenge to operationalization of PHL reduction strategies in many countries of the region. This paper utilizes cross-sectional data to determine the extent and factors that are influencing postharvest losses in the cooking-banana value chain in Uganda. We find that $14.9 \%$ of all the cooking bananas that are produced in Uganda suffer postharvest deterioration along the value chain $(7.2 \%$ of the bananas deteriorate completely and have no residual value, while $7.7 \%$ deteriorate partially and are sold at discounted prices), mostly affecting retailers. At farm level, female headed households experience more losses than those headed by males. Household headship, household size, proportion of land allocated to banana production, and monthly banana production are the principal determinants of PHL at farm level. At retail level, such losses are mainly determined by sex of the vendor and group membership. The findings call for comprehensive and gender-responsive PHL reduction strategies.
\end{abstract}

Keywords: cooking banana; physical postharvest losses; economic postharvest losses; food security; value chain

\section{Introduction}

The reduction of postharvest losses (PHL) reduction has become a central pillar of sustainable global food systems. PHL reflect a missed opportunity in the fight against global food insecurity. The reviews "The Future of Food and Farming" [1] and the "Missing Food" report [2] recommend PHL reduction as a critical response to global food availability concerns. FAO (Food and Agriculture Organization of the United Nations) [3] estimates that one-third, which amounts to 1.3 billion tonnes, of all the food that is produced for human consumption is lost globally. The World Bank [2], for instance, estimates that up to USD 4 billion in value of cereals is lost to PHL in sub-Saharan Africa (SSA); this exceeds the value of food aid received in SSA over the last decade [4]. In such a case, reducing PHL is crucial if the food demands of the ever growing world population are to be met $[5,6]$. Pedrick [7] 
asserts that even without increases in agricultural production, PHL reduction can make a significant contribution to combating hunger and increasing farm incomes. Reduction of PHL is even more crucial in SSA, where approximately 218 million people live on the margins of food insecurity [8]. In light of this, PHL reduction has become a central component of development policy in Africa. PHL reduction is an integral component of the Comprehensive Africa Agriculture Development Plan (CAADP). In Uganda, for instance, PHL reduction is an essential pillar of the second National Development Plan [9].

Despite policy prioritization, operationalization of PHL policies and strategies remains a challenge. One of the main constraints to operationalization of PHL reduction policies and strategies is the lack of clear and empirical information on the magnitudes, distribution, and determinants of these losses. This information is crucial in the identification of solutions and in guiding priorities of action $[3,4,10]$. In this study, we contribute to PHL literature by analysing the extent and determinants of PHL in the green cooking banana (matooke) value chain in Uganda.

Banana is an important source of food and nutrition security for smallholder farmers in Uganda. Annual country production is 8.9 million metric tons [11]. Banana provides $17 \%$ of Uganda's daily caloric requirements [12]. Similarly, on average, each banana cultivating household earns USD 1244 per annum [13]. Uganda is the largest consumer of cooking bananas in the world [14], with an annual per capita consumption of $172 \mathrm{~kg}$ [15]. However, because of a short shelf life, bananas are highly vulnerable to postharvest deterioration [16]. Information on the extent of these losses in bananas is limited. Affognon et al. [4] in a meta-analysis of PHL literature in SSA note that, whereas evidence on PHL in cereals is increasingly available [3,17], only scanty information exists on the extent, distribution, and drivers of PHL in vegetables, roots, and tubers, and fruits, like bananas. Where available, evidence on PHL in banana is mixed: losses of up to $80 \%$ are reported in Rwanda [18]; on season and off-season market losses of $6.6 \%$ and $2.2 \%$ are reported in Nigeria [19]; total value chain losses of $26.5 \%$ are reported in Ethiopia [20]. In the Ugandan context, only TRIAS [21] has attempted to quantify PHL in bananas. However, estimates from this study are anecdotal and are based on secondary review of literature. The study is also silent about the distribution of losses at the different value chain nodes, yet such information is essential in the identification of loss hotspots and can guide targeting of loss reduction strategies. Using a value-chain approach, the current study, first: estimates the extent of postharvest losses in the cooking banana value chain; and, then identifies the factors that affect PHL at value chain nodes with the highest losses. In doing so, the study will underscore strategies and recommendations for reducing PHL, and in turn, will contribute to make the value chain more efficient and sustainable.

The article is structured as follows. In the next section, we present a conceptual framework to show how PHL can be estimated along with the factors that underlie these. We then describe the survey data and the econometric methods of analysis used to identify the determinants of PHL. Finally, we present and discuss the main results and draw conclusions for future research and development efforts.

\section{Conceptual Framework, Data and Methods}

\subsection{Conceptual Framework}

Postharvest losses refer to measurable quantitative and qualitative food losses in the postharvest system [22]. PHL threaten food, income, and nutrition security for smallholders [2]. PHL can be subdivided into "food loss" and "food waste". The distinction between "food loss" and "food waste" is arbitrary and not well defined in PHL literature. The current study follows FAO [10], which distinguishes "food loss" and "food waste" on the basis of the food supply chain stage/level at which losses occur. Losses at farm, collection, wholesale, and retail levels are defined as "food loss", while losses at consumer level are termed "food waste." In this study, losses at the consumer level defined as food "waste" were not used in the estimation of PHL in cooking banana value chain. We define the extent of PHL in the banana value chain to be the sum of losses at farm, collection, 
wholesale, and retail levels, which are hypothesized to be influenced by a number of factors, including social, economic, and infrastructural factors, as shown in Figure 1.

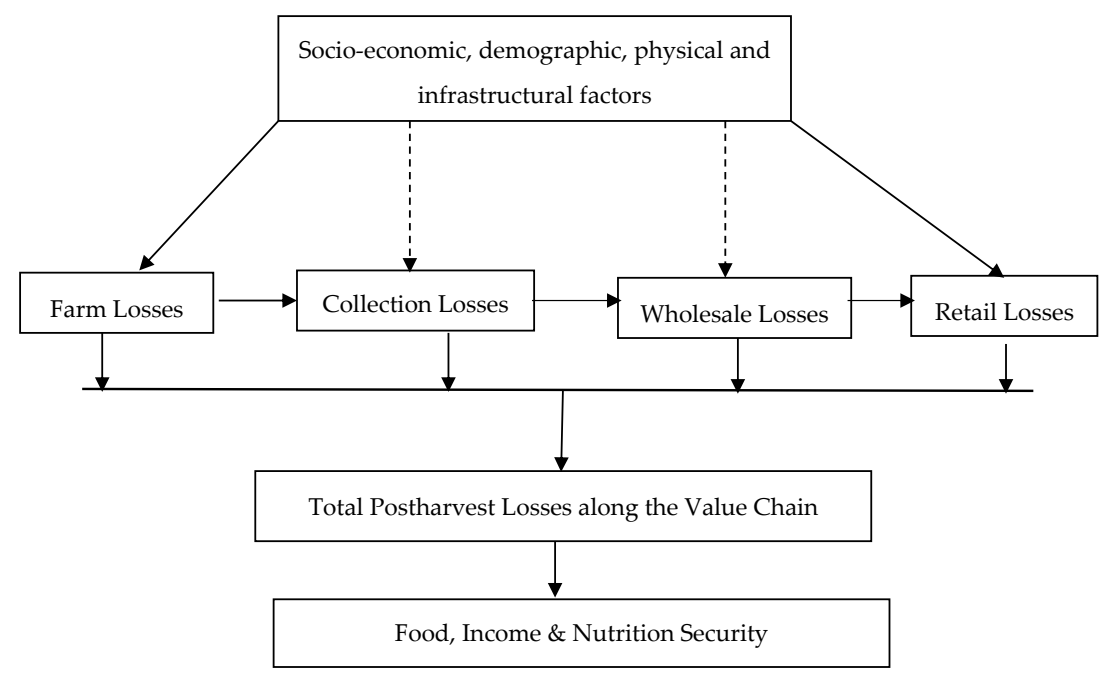

Figure 1. Conceptual Framework for Postharvest Losses (Source: Authors).

\subsection{Data and Data Sources}

This study utilises primary cross-sectional data collected from Isingiro, Rakai, and Kampala districts between July and September 2015. These study areas are shown in detail in Appendix A Figure A1. Rakai and Isingiro were purposively selected because they are among Uganda's biggest banana producing districts [23], while Kampala was selected because it is the leading banana consuming district in the country. Isingiro district is located about $310 \mathrm{~km}$ and Rakai district about 208 km south-west of Kampala, Uganda's largest urban and capital city. One sub-county from both Rakai and Isingiro districts was purposively selected, that is, Dwaniro sub-county in Rakai and Rugaaga sub-county in Isingiro district. The two selected areas are the main banana producing sub-counties in each district. 100 farmers (50 per sub-county) were randomly selected for the survey. Ten wholesalers (lorry traders) and 17 collectors (seven bicycle traders and ten brokers) were also randomly selected in the study to provide information on banana collection and wholesale. Similarly, eight markets in metropolitan Kampala were sampled. A total of 40 retailers randomly selected from these markets. Eight market masters (one per market) were also interviewed to obtain deeper insights about the banana retail market.

Different tools were used for data collection. A structured and pretested questionnaire (for face-to-face interviews) consisting of both open- and closed-ended questions was administered to producers and retailers, while checklists (sets of few open-ended questions) were used to gather information from key informants [including market masters, collectors (bicycle traders and brokers), and wholesalers]. Four enumerators were hired and trained specifically for this study. Prior to the interviews, each respondent was informed about the purpose of the study and the context in which the interview was to be conducted. Respondents were told that their participation is voluntary and their responses will be kept strictly confidential. Consent was sought for each respondent before participation, and each was informed to discontinue participation at any time if chosen so. Finally, each respondent was reminded that there were no right or wrong answers and that the interviewers were only interested in their opinions. During the interview, each question was described carefully, simply, and thoroughly to ensure that the respondents understood the questions asked. A household head (male or female) was interviewed for each selected farming household, while a trader (male or female) was interviewed at other value chain nodes. All of the interviews were conducted in local languages. Responses were checked daily by a supervisor to ensure accuracy, consistency, and completeness. 


\subsection{Estimation of Physical, Economic and Overall Postharvest Losses}

Following Naziri et al. [24], physical losses were estimated as the proportion of banana that is deteriorated to the point that it is unfit for human consumption. Bananas affected by physical losses do not have a residual value or alternative uses (products intended for human consumption and used as livestock feed falls in this category). This includes bananas that were left in the field after harvesting, spoiled bananas that are discarded, and bananas that are eaten up by pests and diseases. Economic losses on the other hand refer to the proportion of bananas that are partially spoiled or damaged and whose market price is discounted as a result. Bananas that are affected by economic losses have a residual value and alternative uses. In this study, we measured both the indicative average prices of good quality bananas and the discounted prices for bananas that have incurred quality deterioration at the different value chain nodes. Similarly, physical and economic losses at farm, collection, wholesale, and retail levels in both scarcity and surplus seasons were estimated. Weighted means, as opposed to simple means across the two seasons were used to obtain the average physical and economic losses at each value chain node. This is because different banana quantities are produced in surplus and scarcity. A simple mean in such a case would produce inaccurate estimates of losses. The relative proportions of bananas produced and marketed during surplus and scarcity were thus used as weights in estimating the average physical and economic losses at the different value chain nodes, as shown in Equation (1) below.

$$
\text { PHL }_{\mathrm{i}}=\left(\text { PHL }_{\text {scarcity }} \times \text { Bananas }_{\text {scarcity }}\right)+\left(\text { PHL }_{\text {surplus }} \times \text { Bananas }_{\text {surplus }}\right)
$$

where $\mathrm{PHL}_{\mathrm{i}}$ is the average amount of PHL (either physical or economic) incurred at the $i$ th VC node; Bananas $_{\text {scarcity/surplus }}$ refers to the proportions of bananas produced or handled during scarcity or surplus season. The sum of the proportions of bananas handled in surplus and scarcity seasons is one (1). $\mathrm{PHL}_{\text {scarcity/surplus }}$ refers to the losses (either physical or economic) suffered during a scarcity or surplus season. The extent of PHL at the $i$ th value chain node were estimated as the sum of the average physical and average economic losses at the $i$ th stage, as shown in Equation (2)

$$
\mathrm{PHL}_{\mathrm{i}}=\text { Physical Losses }_{\mathrm{i}}+\text { Economic Losses }_{\mathrm{i}}
$$

Because partially spoiled bananas can move from the farm to wholesalers, to retailers, and finally, to consumers, the total amount of economic losses in the banana value chain was estimated as a sum of economic losses at each node of the chain. However, since bananas that are physically lost at one node of the chain actually disappear from the value chain and cannot be lost again (they do not move to the next value chain node), the total amount of physical losses along the whole chain were calculated by summing up the losses at each node of the VC netting off losses that had occurred at the previous stage in order to avoid double counting (this is more rigorous than simply summing up the relative losses of all stages).

\subsection{Regression Models}

The current study also assessed the determinants of postharvest losses at farm and retail level. These two levels were considered for further analysis because: first, the deterioration of marketable banana originates from the farm, understanding the factors contributing to this deterioration could be useful in reducing losses as the product moves along the value chain; and second, the highest PHL occur at the retail level, understanding loss drivers could also help in reducing retail losses. We employed a multiple linear regression model following Basavaraja et al. [25], Adewumi et al. [19], and Mebratie et al. [20] to assess the determinants of postharvest losses at farm and retail levels, as explicated in Equation (3).

$$
\text { Total PHLi }=\sum S_{i}=\sum f\left(X_{j}\right)
$$


where $S_{i}$ is the loss at the $i$ th level of the value chain and $X_{j}$ are the factors affecting losses at producer or retailer level in the VC. The general equation can be specified as

$$
Y_{i}=\beta_{0}+\beta_{1} X_{1}+\ldots+\beta_{n} X_{n}+\mu
$$

where $Y_{i}$ are the PHL at $i$ th level, $X_{1}$ to $X_{n}$ is a vector of explanatory variables, and $\mu$ is a random error term. A significant number of producers interviewed reported zero PHL. As a result, we employed a tobit censored regression model to obtain robust estimates of the factors affecting postharvest losses at the farm level. The tobit or censored regression model, as suggested by Tobin [26], is used in situations in which $y$ is observed for values greater than zero, but is not observed (that is censored) for values of zero or less. The standard Tobit model is defined as;

$$
\begin{gathered}
y_{i}^{*}=\beta X_{i}+\varepsilon_{i} \\
y_{i}=y_{i}^{*}, \text { if } y_{i}>0 \\
y_{i}=0, \text { if } y_{i} \leq 0
\end{gathered}
$$

where $y_{i}^{*}$ is the latent dependent variable, $y_{i}$ is the observed dependent variable, $X_{i}$ is a vector of the independent variables, $\beta$ is the vector of coefficients, and the $\varepsilon_{i}$ is assumed to be independently normally distributed: $\varepsilon_{i} \sim \mathrm{N}\left(0, \sigma^{2}\right)$ (and therefore $y_{i} \sim \mathrm{N}\left(\beta X_{i}, \sigma^{2}\right)$ ). It should be noted that observed zeros on the dependent variable could mean either "true" zero or censored data. Some of the observations in the model must be true zero censored data, or $y_{i}$ would always equal $y_{i}{ }^{*}$ and the true model would be a linear regression not Tobit. Various checks were performed to best fit our model. Normality and linearity assumptions for continuous explanatory variables were assessed before the models were estimated. We used different diagnostic procedures to check for outliers, multicollinearity among the continuous independent variables, and the homogeneity of variance assumption. We calculated standard residuals, student residuals, and DFBETAs to check for outliers. We also examined a scatter plot of the residuals against the predicted values to evaluate whether the assumption of homogeneity of variance is not violated. The Variance Inflation Factor (VIF) was also calculated to check for multicollinearity.

\subsection{Description of Dependent and Independent Variables}

The independent variables in the producer and retailer regression models and their hypothesized signs are shown in Table 1 below. The independent variables for producers and retailers were estimated, as follows; age was calculated as the number of complete years for both producers and retailers; dummy variables for sex and group membership were determined and male/group membership was coded as 1 and female/non-group membership was coded as 0 ; for education, two categories that is to say at least completed secondary education and above coded as 1 and no secondary education and below coded as 0 . Total annual production reflects the number of bunches farmers produce annually, while quantity sold is the number of bunches retailers sell monthly. Market access was proxied by distance to markets and distance to tarmac road. Experience is measured as number of complete years a retailer has been in business. Farm size is the number of acres of farm land owned by a farmer, which is a proxy for wealth. Household size (a proxy for farm labor) was calculated as the number of people living in the household. Following Beaman and Dillon [27], a household was defined as "a group of people who normally live and eat their meals together in the household, and members must acknowledge the authority of one person as head of household and that person must live with the rest of the household members." A varietal dummy (Kibuzi = 1) was also included. Kibuzi variety is perceived by farmers to have the longest intrinsic shelf-life when compared to all other varieties. It is expected that PHL are lower if you grow such varieties on farm. 
Table 1. Expected Signs of Independent Variables for the Farm Level and Retail Regression Models.

\begin{tabular}{|c|c|c|c|c|}
\hline Variable & $\begin{array}{c}\text { Expected Signs (Farmer } \\
\text { Model) }\end{array}$ & Reference & $\begin{array}{c}\text { Expected Signs (Retailers' } \\
\text { Model) }\end{array}$ & Reference \\
\hline Age (years) & - & Mebratie et al. (2015) & & \\
\hline Male respondent (vs. female) & $-/+$ & $\begin{array}{l}\text { Mebratie et al. (2015) ; Aidoo et al. (2014); } \\
\text { Kaminski \& Christiaensen (2014) }\end{array}$ & + & Mebratie et al. (2015) \\
\hline Secondary education (vs. below secondary) & - & $\begin{array}{l}\text { Basavaraja et al. (2007); Kaminski \& } \\
\text { Christiaensen (2014) }\end{array}$ & - & Mebratie et al. (2015) \\
\hline Experience (years) & & & - & Adewumi et al. (2009) \\
\hline Group Membership (vs. no membership) & - & $\begin{array}{l}\text { Mebratie et al. (2015); Adewumi et al. (2009); } \\
\text { Aidoo et al. (2014) }\end{array}$ & - & Adewumi et al. (2009) \\
\hline Household Size (No. of HH members) & - & Basavaraja et al. (2007), Aidoo et al. (2014) & & \\
\hline Market access $(\mathrm{Km})$ & - & Kaminski \& Christiaensen (2014) & & \\
\hline Farm size (acres) & + & Aidoo et al. (2014) & & \\
\hline Quantity Produced (bunches) & + & Basavaraja et al. (2007) & & \\
\hline Quantity Sold (bunches) & & & - & Mebratie et al. (2015) \\
\hline Banana variety (Kibuzi) & - & & & \\
\hline Bananas consumed at home (\%) & + & & & \\
\hline Land under bananas (\%) & + & & & \\
\hline $\begin{array}{c}\text { Source of bananas (nearby Markets, lorry } \\
\text { traders, farmers) }\end{array}$ & & & $+/-$ & \\
\hline $\begin{array}{l}\text { Information shared with suppliers (availability, } \\
\text { price and quality) }\end{array}$ & & & $+/-$ & \\
\hline
\end{tabular}




\section{Results and Discussion}

\subsection{Structure of the Cooking Banana Value Chain}

The chain is made up of producers, collectors (brokers and bicycle traders), wholesalers, retailers, consumers, and exporters, as explicated in Figure 2 below. Bananas move from producers to lorry traders (wholesalers) directly or through collectors (brokers and bicycle traders). The lorry traders then transport and distribute the bananas to the retailers who then sell to the final consumers in the domestic market. Some bananas move directly from producers to exporters, who mostly sell to Europe and regional markets, especially South Sudan. The volume of bananas exported however remains very small (estimated at less than $5 \%$ of total production) and this is not included for this study. This study focused mainly on the domestic cooking-banana market.

Bicycle traders, which are common in Rakai district, buy bananas from farmers that were dispersed within the village; they act as initial collecting agents. Bicycle traders are well-known members of the community and have established relationships with the farmers. Competition exists amongst bicycle traders as barriers to entry are low. Bicycle traders sell most of their produce to brokers at collection centre that are found at sub-county or district trading centers. Smaller percentages (20\%) of their sales go to local consumers, market vendors, or lorry traders directly. At times, brokers collect bananas directly from farmers though they buy most of their bananas from bicycle traders. Brokers, in turn, supply the bananas to lorry traders (wholesalers); they are commission agents linking bicycle traders to lorry traders. In a few circumstances, brokers engage in the transportation of banana to urban markets.

Retailers (vendors) operate in small stalls in major urban markets. The major key banana markets in Kampala city are Kalerwe, Nakawa, Kasubi, and Nakasero, but there are several other smaller markets in the Kampala metropolitan area where retailers operate. Retailers purchase most of their stock from lorry traders (wholesalers), while a few purchase directly from producers (who doubles as traders) or other large retailers in the same or neighbouring markets. Vendors have long term strong relationships with lorry traders and they usually negotiate banana prices on phone before the bananas are delivered in the markets. Retailers, in turn, sell bananas mostly to individual urban household consumers and restaurants.

\subsection{Socio-Economic Characteristics of Value Chain Actors}

From Table 2, male dominance at most value chain nodes is evident. At wholesale and collection, all of the traders in the study were males. Our findings are similar to Mebratie et al. [20] who find males to dominate the banana value chain in Ethiopia. The results also show that most of the respondents were married. Retailers were found to be the most educated, followed by the producers, while wholesalers were the least educated.

Producers were more likely to belong to a farmers' group. Only a handful of retailers, wholesalers, and bicycle traders belonged to any group. Brokers did not belong to any group. Results further show producers, wholesalers, and brokers to be older and retailers and bicycle traders to be younger. This may be because production, brokerage, and wholesale activities are capital intensive (in form of land or cash). Older people with more resource endowments are more likely to participate in resource intensive activities, like the production and wholesale of bananas. Younger people with limited capital endowments may only afford to participate in less capital-intensive activities. This may explain the lower mean age for retailers and bicycle traders. Retailing and bicycle trading are also labor intensive and may be more suited to younger people who are usually more energetic. The mean overall proportion of land under banana was 23\% (33\% in Isingiro district and 15\% in Rakai district). 
Table 2. Socio Economic Characteristics of Value Chain Actors.

\begin{tabular}{|c|c|c|c|c|c|c|}
\hline \multirow{2}{*}{ Variable } & \multirow{2}{*}{ Characteristics } & \multirow{2}{*}{ Producers } & \multicolumn{2}{|c|}{ Collectors } & \multirow{2}{*}{ Wholesalers } & \multirow{2}{*}{ Retailers } \\
\hline & & & Bicycle Traders & Brokers & & \\
\hline \multirow{2}{*}{ Sex $(\%)$} & Female & 42 & 0 & 0 & 0 & 40 \\
\hline & Male & 58 & 100 & 100 & 100 & 60 \\
\hline \multirow{2}{*}{ Education (\%) } & No Secondary & 54 & & & 80 & 42.5 \\
\hline & At least Secondary & 46 & & & 20 & 57.5 \\
\hline \multirow{2}{*}{ Group membership } & Yes & 93 & 14.3 & 0 & 20 & 25 \\
\hline & No & 7 & 85.7 & 100 & 80 & 75 \\
\hline \multirow{4}{*}{ Marital status (\%) } & Married & 84 & & & 100 & 87.5 \\
\hline & Single & 3 & & & 0 & 10 \\
\hline & Widow/widower & 11 & & & 0 & 0 \\
\hline & Separated & 2 & & & 0 & 2.5 \\
\hline Experience (years) & & & & & & $9.8(7.9)$ \\
\hline Total Land (acres) & & $11.1(16.5)$ & & & & \\
\hline Proportion of land under banana (\%) & & 23.5 & & & & \\
\hline Age (years) & & $47.5(10.7)$ & $33.4(3.9)$ & $40.0(10.2)$ & $40.4(5.5)$ & $36.8(7.9)$ \\
\hline Household size & & $7.5(3.1)$ & & & & \\
\hline
\end{tabular}

Note: Values in parentheses are standard deviations 


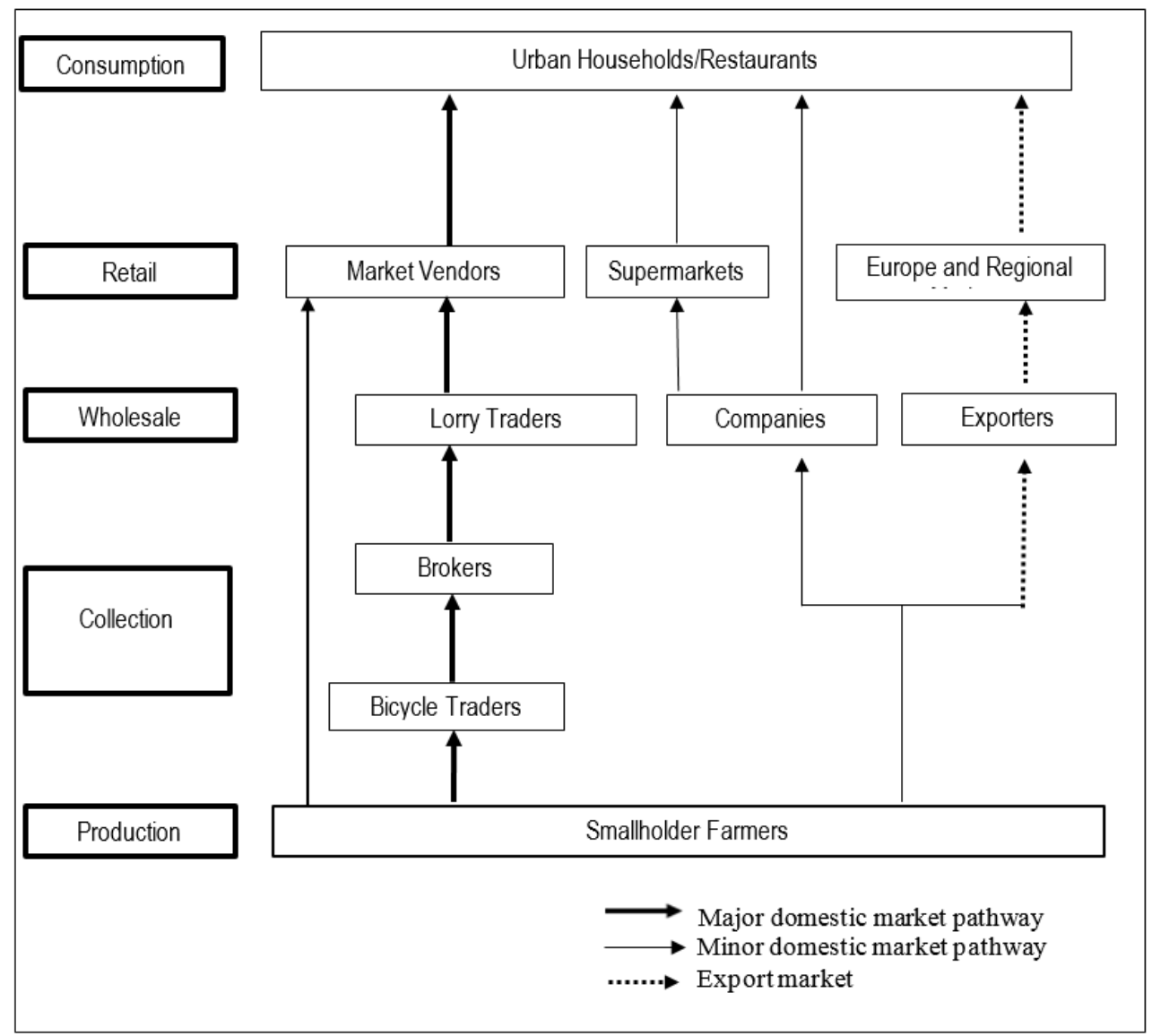

Figure 2. Structure of the Cooking Banana Value Chain in Uganda (Source: Authors).

\subsection{PHL in the Cooking Banana Value Chain}

\subsubsection{Seasonal Variation of PHL at Each Node}

Postharvest losses are proportionally higher in the high production (surplus) season than in the low production (scarce) season. At times of scarcity, physical losses and economic losses affect about $1.2 \%$ and $1.9 \%$ of harvested bananas, respectively, on farm (Table 3). Due to quality deterioration (economic losses), a bunch is sold at a discount rate of about $25 \%$ in the scarce season at farm level. The major causes of physical losses at farm level are theft and ripening, while the causes of economic losses are mainly selling of immature bananas, followed by poor postharvest handling and ripening. Selling immature bananas is attributed to the high demand in the market that cannot be met by the available farm production during times of scarcity. Immature bananas are considered to be of low quality and thus buyers pay less than the normal price of a mature bunch. During the surplus season, physical losses are estimated at 3.4\%, while economic losses affect approximately $2.8 \%$ of harvested bananas that are sold at $65 \%$ price discount. The major cause of postharvest (physical and economic) losses during the surplus season is ripening. During the surplus season, there are many producers offering bananas to the market yet buyers are few. As a result, some farmers fail to sell their bananas, while others store their bananas for longer periods predisposing them to ripening.

At the collection level, proportionally larger losses are incurred during the surplus season $(3.9 \%$ and $4.6 \%$ of bananas affected by physical and economic losses, respectively, resulting into a $20 \%$ price discount for the latter) when compared to the scarcity season $(1.8 \%$ and $2.2 \%$ of bananas affected by physical and economic losses, respectively, with a $16 \%$ price discount for the latter). Bruising, ripening, and overstaying are the lead causes of physical and economic losses in both the surplus and scarcity seasons. It must be noted that the economic losses reported at collection, wholesale, and retail levels in 
Table 3 are cumulative and are not actual (net) economic losses that are incurred at those particular nodes. For example, during scarcity, the observed economic losses at the collection level was $2.2 \%$. However, this includes economic losses incurred at farm level (1.9\%). The actual economic losses incurred at this node, therefore, is only $0.3 \%$. That is to say, all of the economic losses reported in this section are cumulative. Actual losses are discussed in estimating the extent of postharvest losses in the chain later in the paper.

At the wholesale level, physical losses during scarcity are estimated at $6.7 \%$ and economic losses at $3.2 \%$. Due to quality deterioration, a bunch is sold at about $13 \%$ price discount. The major causes of such losses are thefts and bruising for physical losses and bruising and ripening for economic losses. However, in the surplus season, both physical and economic losses increase to $8.7 \%$ and $7.5 \%$, respectively, and they are mainly caused by ripening and bruising. Quality deterioration leads to selling each bunch at a discount rate of approximately $33 \%$.

At retail level physical losses during periods of scarcity are estimated at about $6.2 \%$, while economic losses affect approximately $6.5 \%$ of traded banana whose price is reduced by about $52 \%$. At times of surplus physical losses increases to $9.8 \%$ and volumes affected by economic losses almost double to $11.9 \%$, resulting into $60 \%$ discounted selling price per damaged bunch. Physical losses are mainly caused by ripening, bruising, and thefts, while economic ones are caused by ripening, bruising, and finger plucking in scarcity seasons. Generally, workers who load (and offload) bananas onto (from) the truck are not paid cash. So at any point of loading and offloading these workers pull out (pluck) some banana fingers as their in-kind payment. On average about 10 fingers are removed per bunch. Retailers are very dissatisfied with the act of plucking out fingers from the bunch and about $57 \%$ of the retailers reported tremendous losses (due to weight loss and accelerated quality deterioration) from finger plucking. Bruising and ripening are the lead causes of postharvest (both physical and economic) losses during the surplus season at the retail level. Bruising results into discoloration and exposes the banana to infections thus shortening the shelf life and lowering the quality. Other causes that have been mentioned include overstaying, scotching (drying/shrinking due to exposure to prolonged sunlight), and finger plucking.

Table 3. Seasonal Physical and Economic Postharvest Loss (PHL) at Different Levels of the Value Chain.

\begin{tabular}{ccccccc}
\hline \multirow{2}{*}{ Value Chain Level } & \multicolumn{2}{c}{ Physical Loss (\%) } & \multicolumn{2}{c}{ Economic Loss (\%) } & \multicolumn{2}{c}{ Price Discount (\%) } \\
\cline { 2 - 7 } & Scarcity & Surplus & Scarcity & Surplus & Scarcity & Surplus \\
\hline Farm & 1.2 & 3.4 & 1.9 & 2.8 & 25 & 65 \\
Collection & 1.8 & 3.9 & 2.2 & 4.6 & 16 & 20 \\
Wholesale & 6.7 & 8.7 & 3.2 & 7.5 & 13 & 33 \\
Retail & 6.2 & 9.8 & 6.5 & 11.9 & 52 & 60 \\
\hline \multicolumn{7}{c}{ Source: Authors. }
\end{tabular}

\subsubsection{Weighted PHL at the Value Chain Nodes}

Survey data shows that approximately $36.5 \%$ of cooking bananas are produced and marketed in the scarce season, while $63.5 \%$ are produced and traded during the surplus season. The proportions of bananas in these two seasons were used as weights for calculating the average amount of banana affected by physical and economic losses at the various nodes of the value chain, as shown in Figure 3. As hypothesized, the weighted means gave better estimates than simple unweighted means, which underestimate the losses. PHL from simple means are attached in Figure A2 for comparison. 


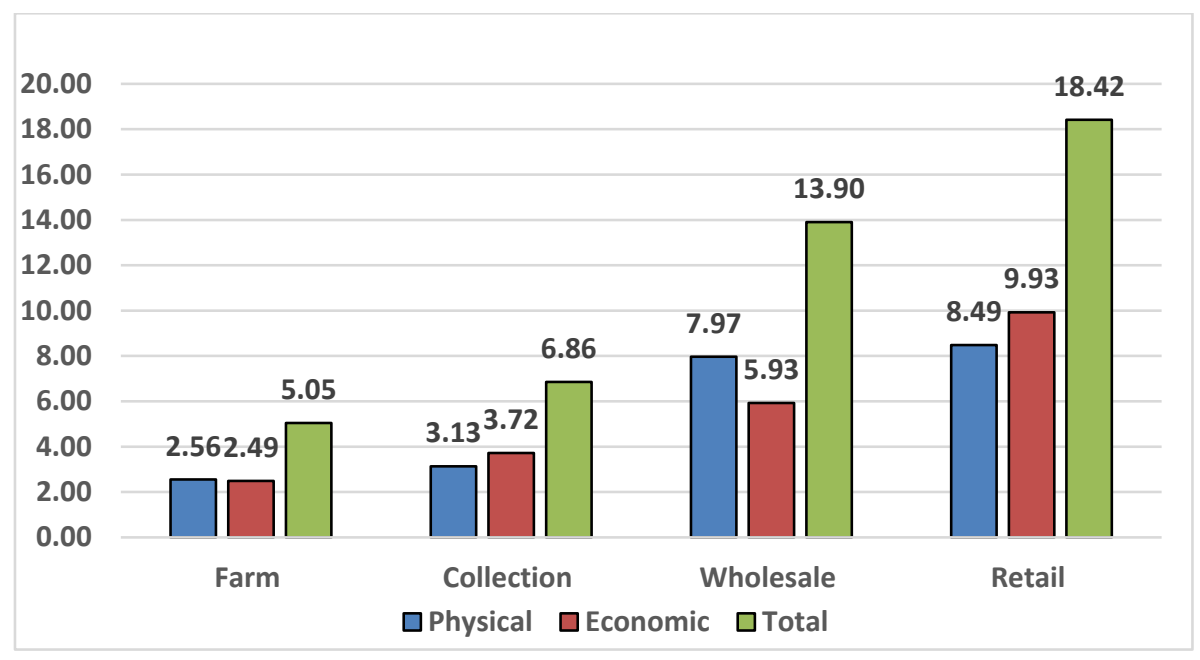

Figure 3. Percentage of physical, economic, and total postharvest losses along the banana value chain (Source: Survey data).

Results show that substantial amounts of banana are lost on farm. Losses at this level are caused by pests and diseases, poor harvesting practices, poor husbandry practices, and excessively long storage periods as farmers look for market. These result into bruising, ripening and splitting of banana fingers. Off the farm, bananas spoil more as they move along the value chain with cumulative effects of mishandling manifesting more as bananas move along the value chain. As a result, bruising and ripening are therefore more prevalent at retail level. From Figure 2, it can be observed that most PHL (both physical and economic) occur at the retail level. Our findings are similar to Mebratie et al. [20] in Ethiopia who report banana PHL at retail level to be $14.9 \%$ and Wanjari \& Ladaniya [28] who report physical banana losses at retail level to be $2.85 \%$ in India. In contrast, collectors and wholesalers handle mostly greener and fresher bananas that suffer less deterioration; this may explain why they incur relatively lower losses when compared to retailers. Collectors suffer the lowest losses in the value chain. This may be because they handle the crop for only limited periods transporting it over very short distances as they connect producers to wholesalers.

\subsubsection{Extent of Postharvest Losses in the Banana Value Chain}

In this study, the extent of postharvest losses in the banana value chain is estimated as the sum of the total physical and total actual economic losses in the value chain. However, it is extremely important to take into account that we found that on average, only about $35 \%$ of the total harvested cooking bananas actually leaves the farm for the market, the rest being consumed by the farm household.

Therefore, in calculating the total extent of physical losses in the chain, it was assumed that $65 \%$ of harvested banana incurs only on-farm losses (2.6\%), while the remaining 35\% (i.e., marketed banana) is affected by losses at all stages of the value chain, including on-farm. In computing the proportion of marketed bananas affected by physical losses we net off losses that are incurred at previous value-chain nodes since the produce lost at one node does not move to the next node (and cannot be lost again). Our results show that that $20.6 \%$ of traded banana is lost along the chain $(1-0.974 \times 0.969 \times 0.920$ $\times 0.915)$. It is worth noting that a direct sum of physical losses at the respective value-chain nodes without netting off losses at previous chains would have overestimated the physical losses at $22.2 \%$. If the physical losses value of $20.6 \%$ obtained is extrapolated for all of the bananas produced in Uganda, it translates into a physical losses value of $8.9 \%$.

The total PHL value of economic losses was calculated as a direct sum of the actual (net) economic losses at farm, collection, wholesale, and retail levels, resulting into a value of $9.9 \%$ 
$(2.5+1.3+2.2+4.0)$, translating into an overall economic losses value of $3.5 \%$ for all of the cooking bananas produced in the country.

We then sum up the physical and economic losses to obtain the extent of PHL in the entire chain approximating to $12.4 \%$ of harvested bananas (corresponding to $30.5 \%$ of the traded bananas), of which $8.9 \%$ are completely lost, while $3.5 \%$ are sold at a discount due to quality deterioration.

PHL estimates from our study are considerably lower than the ones that were reported by the National Agricultural Research Organization, which estimates that over 35\% of fruits and vegetables that are produced in Uganda are lost after harvest [29]. Our PHL estimates are also lower that the ones that were reported by FAO [3], which estimates the global value of PHL for fruits and vegetables to be $45 \%$ of total production. The low value of our estimates can be attributed to our adoption of a more rigorous estimation methodology, which eliminates double counting and controls for the bananas that are auto-consumed by the producing households. In addition, our results show that PHL in Uganda are lower than in Ethiopia where losses of $26.5 \%$ are reported in plantains [20].

Our results also show that PHL in cooking bananas are approximately threefold the losses that are incurred in cereals in Uganda. Kaminski \& Christiaensen [17] report PHL for maize in Uganda to be $5.9 \%$. Findings from our study fit into Aulakh et al.'s [30] argument that perishables, like fruits and vegetables, are subject to the greatest proportions of PHL in developing countries because of the underdeveloped links between supply chain nodes in these countries.

\subsection{Differences Between Producers and Retailers}

Table 4 shows the descriptive statistics for the common variables used in econometric analysis. For the outcome variable, the proportion of banana incurring either physical or economic PHL, results show that retailers suffer higher PHL than producers. For the independent variables, education and sex were not significantly different between producers and retailers. However, differences in age and group membership are observed. Producers are more likely to belong to a group when compared to retailers. The data also shows that older people are more likely to engage in the production of bananas, while younger ones are more in retailing. This maybe because retailing in Kampala markets is a labourrather than capital-intensive activity, which is more suited for younger people.

Table 4. Differences in Variables Used in Econometric Analysis.

\begin{tabular}{ccccc}
\hline & Producers & Retailers & \\
\hline Variable & Mean & SD & Mean & SD \\
\hline Outcome Variable & & & & \\
Postharvest Losses (\%, weighted) & 5.05 & & 18.42 & \\
Independent Variables & & & & \\
Group Membership (1 Yes: 0 = No) & $0.93^{* * *}$ & 0.26 & 0.25 & 0.44 \\
Secondary Education (1 Yes: 0 = No) & 0.46 & 0.50 & 0.58 & 0.50 \\
Sex (1 Male: 0 = Female) & 0.58 & 0.50 & 0.60 & 0.50 \\
Age (Years) & $47.45^{* * *}$ & 10.65 & 36.85 & 7.91 \\
\hline
\end{tabular}

Note: SD means Standard Deviation: ${ }^{* * *}$ denotes that mean values between producers and retailers are significantly different at $1 \%$.

\subsection{Mitigation Measures for Postharvest Losses}

At production level, farmers suggested that if they can even out the supply throughout the year, then the tremendous losses in the surplus season will be reduced. All of the value-chain actors agreed that producing and marketing varieties with longer shelf life (as well as those that are more demanded by the market) can help to reduce losses that are caused by ripening. Farmers suggested that training in proper harvesting time can reduce immature harvests, thus reducing losses arising from selling immature bananas. Similarly, farmers hinted that fencing off banana plantations can help to reduce losses due to theft, but it would be costly to implement. Lorry traders suggested that improving roads 
in rural areas, transporting bananas at night (when temperatures are low) and proper packing of bananas on trucks can reduce losses during transportation. At the retail level, about half of the vendors also suggested that avoiding overloading could reduce bruising during transportation to the market. All of the value-chain actors believe that proper handling of bananas right from the farm to the market can reduce bruises. Finally, covering bananas with tarpaulins (perforated to avoid heat build-up) after harvest at farm level, during transportation, and at retail markets can reduce the exposure of bananas to direct sunlight, which in turn, can minimize losses as a result of scorching.

\subsection{Determinants of Postharvest Losses at Farm Level}

In determining the factors that affect postharvest losses at the farm level, we used both ordinary least squares (OLS) regression and Tobit regression. The R squared value for the OLS model was 0.637, and the model passed all the diagnostic tests performed. The DFBETAs, student, and standard residuals for the OLS model, were all within the prescribed limits. However, because 24 observations of the dependent variable had zero observations, a Tobit model was estimated. This is because using the common linear specification for models, such as OLS with a censored dependent variable, may result in biased estimates [31]. The Tobit model fitted better than OLS model (i.e., $\chi^{2}(15)=86.3$; Prob $>\chi^{2}=0.000$ ). As explained, the determinants of PHL at farm level are discussed based on the Tobit estimates. The factors influencing postharvest losses at the production level are presented in Table 5. These estimates build on Equation (5), with total annual PHL as the dependent variable.

Results show that sex of the household head, household size, education, monthly production of bananas, specialization (proxied by the proportion of total land under bananas), and an interaction between district (Rakai $=1$ ) and distance to tarmac road significantly influence the level of PHL at farm level. First, female headed farm households experience higher levels of PHL than the male-headed ones. This might be because of the intensive nature of banana production and marketing. Males in male-headed households are usually in charge of looking for markets, and, thanks to their greater mobility; that is, they tend to travel long distances away from their respective villages searching for markets for their produces, inputs, and other household needs when compared to female farmers [31-33]. In so doing, men can even sell their banana to distant markets and this can reduce the level of physical losses, especially through ripening when compared to their female counterparts who mostly sell their bananas on farm. These results are similar to Mebratie et al. [20] who found female headed households to incur higher postharvest losses than male headed households in Ethiopia. Contrary to findings by Aidoo et al. [34], our results find that household size has a positive and significant coefficient. This could be that larger households (a proxy for labor) are more likely to grow more banana, and in turn, more likely to experience higher PHL, especially during surplus seasons. Furthermore, access to markets (proxied by distance to market and distance to tarmac roads) was found to have insignificant negative effects on PHL, but an interaction between distance to tarmac with the district variable (where Rakai district $=1$ and Isingiro district $=0$ ) resulted into a significant negative effect. This implies that farmers who are far from tarmac roads in the Rakai district (i.e., mean distance to tarmac is $14.4 \mathrm{~km}$ ) have lower losses than Isingiro farmers who are further away from tarmac roads (i.e., mean distance to tarmac road of $39.7 \mathrm{~km}$ ). This could be attributed to the levels of production in the two sites. Descriptive statistics shows that households in Isingiro produced approximately 450 more banana bunches (on 33\% of the total land owned) per month when compared to the surveyed households in Rakai (occupying only 15\% of the land owned). Similarly, UBOS (Uganda Bureau of Statistics) [23] rank Isingiro as the biggest banana producing district in Uganda, and most of its banana producing farmers are far away from the tarmac road. Most farmers in Isingiro are therefore likely to incur more losses than Rakai district farmers with lower monthly production. Similarly, our results show that farmers producing more bananas per month experience significantly higher PHL than those that are producing fewer bunches per month. PHL have been found to be positively associated with the level of production $[19,24]$. In addition, farmers with at least secondary education have lower PHL than their counterparts with less education. Lastly, farmers who are more specialized 
and commercially orientated, (whose land is mostly occupied by banana) experience less PHL. In fact, commercial farmers are more aggressive at searching for markets, and this can help in reducing the physical losses they are likely to encounter. However, other factors, such as age of the household head, banana variety (using Kibuzi, with a longer shelf life), wealth (measured as total land), and group membership have no significant effects on PHL.

Table 5. Determinants of PHL at Production Level.

\begin{tabular}{|c|c|c|}
\hline Variables & Coefficients (OLS) & Coefficients (Tobit) \\
\hline Female headed households & $7.598 * * *(2.152)$ & $9.086^{* * *}(2.574)$ \\
\hline Age & $-0.07(0.072)$ & $-0.121(0.088)$ \\
\hline Household size & $0.553^{* *}(0.273)$ & $0.768^{* *}(0.315)$ \\
\hline Distance to tarmac road & $-0.126 *(0.066)$ & $-0.093(0.074)$ \\
\hline Distance to market & $-1.658 *(0.843)$ & $-1.259(0.951)$ \\
\hline District $($ Rakai $=1)$ & $-13.107^{* *}(5.393)$ & $-7.123(6.583)$ \\
\hline Kibuzi variety & $0.070 *(0.040)$ & $0.064(0.046)$ \\
\hline Secondary Education & $-2.915 *(1.592)$ & $-3.496 *(1.896)$ \\
\hline Total land & $-0.139(0.0982)$ & $-0.163(0.114)$ \\
\hline Monthly banana production & $0.013 *(0.007)$ & $0.015^{* *}(0.008)$ \\
\hline District ${ }^{*}$ distance to market (Rakai district $\left.=1\right)$ & $1.636 *(0.875)$ & $0.870(1.050)$ \\
\hline District * distance to tarmac road (Rakai district $=1$ ) & $-0.367(0.300)$ & $-0.812 * *(0.364)$ \\
\hline Home consumption & $0.021(0.033)$ & $0.041(0.039)$ \\
\hline Land under bananas (\%) & $-0.132 * * *(0.049)$ & $-0.171^{* * *}(0.057)$ \\
\hline Group Membership & $-3.414(2.942)$ & $-3.666(3.360)$ \\
\hline \multicolumn{3}{|l|}{ Model statistics } \\
\hline Observations & 90 & 90 \\
\hline Constant & $24.004^{* * *}(6.312)$ & $23.546^{* * *}(7.389)$ \\
\hline R-Squared & 0.637 & \\
\hline LR (Chi2 (15) & & $86.30^{* * *}$ \\
\hline VIF (overall) & 6.68 & \\
\hline
\end{tabular}

Note: Numbers in parentheses are standard errors. ${ }^{* * *},{ }^{* *}$, and ${ }^{*}$ refer to significance at $1 \%, 5 \%$ and $10 \%$ levels, respectively.

\subsection{Determinants of Postharvest Losses at Retail Level}

We used ordinary least squares regression to determine the factors that influence postharvest losses at the retail level. The R-squared of the model was 0.584 , implying that $58.4 \%$ of the retailers' losses were explained by the explanatory factors in the model. The mean VIF was 1.34, meaning that the explanatory factors were independent of each other. The DFBETAs, student, and standard residuals were within the acceptable limits of -2 and 2 . The Cook's distance values of all the explanatory variables in the model were also between the acceptable ranges of 0 and 1 . This means that no one single explanatory variable had a great effect on the dependent variable (postharvest losses).

Regression results in Table 6 show that sex, group membership, source of bananas, and information shared with suppliers are key factors in determining PHL at the retail level. The negative coefficient for sex shows that female vendors have lower losses in comparison to their male counterparts. This finding is consistent with Mebratie et al. [20], who report female banana retailers to have lower losses in Ethopia. The underlying reason could be that female retailers are better handlers of bananas. Results further suggest that retailers who are in groups have lower PHL than non-members. Through collective action, group members usually purchase in bulk at lower prices directly from producers, this gives group members access to clean, mature, and fresh banana fruits at lower prices, which may allow for them to have a higher turnover and lower losses. Furthermore, sources of banana bunches/fingers and the information shared with suppliers also affected the level of PHL significantly. Retailers who source banana bunches from nearby markets and directly from producers have lower PHL than those who purchase from suppliers who are mostly wholesalers from distant areas. It can be argued that retailers who source their own bananas (for instance from the farm) do more quality assurance, and therefore 
purchase bananas with less damage, and this directly translates into lower PHL. Depending on the type of information shared with suppliers, results further show that retailers who mostly sought information on prices have higher losses than those who seek for information on quality (quality measured as freshness of the banana bunch/fingers). Traders that are mostly interested in prices may pay less attention to inspection and quality assurance, and, as a result, experience higher losses resulting from bruising and ripening.

Table 6. Estimated Ordinary Least Squares (OLS) Regression for Retailers' Determinants of PHL.

\begin{tabular}{cc}
\hline Variables & Coefficients \\
\hline Female vs. male retailer & $6.468^{* * *}(1.751)$ \\
Group member vs. non-member & $-4.556^{* *}(1.848)$ \\
Less than one-year experience in banana vending vs. one year and above & $-0.360(1.763)$ \\
Number of banana purchases in a week & $0.162(0.099)$ \\
Buy from nearby markets vs. buy from suppliers & $-8.902^{* * *}(2.423)$ \\
Buy from producers directly vs. buy from suppliers & $-6.315^{* *}(2.550)$ \\
Price information vs. quality information & $3.006(1.872)$ \\
Availability information vs. quality information & $4.431 *(2.286)$ \\
At least secondary education vs. below secondary & $-2.149(1.638)$ \\
Model statistics & \\
Constant & $23.426^{* * *}(3.636)$ \\
Observations & 40 \\
R-squared & 0.584 \\
Mean VIF & 1.34 \\
\hline
\end{tabular}

Note: numbers in parentheses are robust standard errors. ${ }^{* * *},{ }^{* *}$, and ${ }^{*}$ significant at $1 \%, 5 \%$ and $10 \%$ levels of significance.

\section{Conclusions}

This study examined the extent and determinants of postharvest losses in the cooking banana value chain in Uganda. The results show that reliable estimation of PHL along the chain depend not only on the quality of the data collected-often a major challenge in the midstream and downstream segments of a value chain-but also on adequately taking into account specific value chain characteristics, such as storage and handling at the farm level, during transport, and at the retail outlets. We have shown that a solid estimation that helps to prioritize interventions and policy change should: (1) be mindful of the end-use destination of the crop (market vs. own-consumption); (2) focus on both physical and economic losses as the latter affect a higher proportion of traded produce; (3) determine the physical and economic losses along the different stages of the chain and for the chain as a whole; and, (4) account for the relative and absolute weight of a given crop across different types of production systems. PHL need to be understood in a broader context, including economic considerations, environmental externalities (e.g., avoidable greenhouse gas emissions linked to the produce that eventually is lost), and social aspects (e.g., labor that could have been invested in alternative farming or income generating activities). The total volume of PHL will be a critical parameter for such integrated assessments.

In the case of our study, PHL affects $14.9 \%$ of the produced volume of cooking bananas, translating into 1.1 million tons/year lost in terms of physical or economic losses along the value chain. This represents significant food losses to consumers, equivalent to $21.3 \mathrm{~kg}$ per person per year, along with considerable income losses to producers, wholesalers, and retailers. Strategies to reduce PHL need to focus on the different stages where these occur, particularly at the retail level, but also at the farm, transport, and wholesale levels. Such integrated strategies would include, for example, utilising ripened cooking banana fingers as a source of raw material for processing into another product, such as pancakes (locally known as Kabalaga). This would contribute to transform some of the physical losses into economic losses at the farm and retail levels, as there is still a product to sell, even if at lower price. Further interventions include the development of product and handling standards from production 
through consumption. At the transport level, moving bananas in boxes would protect against bruising, minimizing both physical and economic losses. At retail level, interventions can foster innovations, such as selling of bananas as fingers and clusters, as opposed to bunches, using ripening control chemicals, like ethylene for timebound selling, and offering packed and peeled bananas for increased shelf life and as convenience food. Peeled bananas have numerous advantages, as the peels can be used for on-farm production of organic manure, reducing transport weight, and minimizing waste in urban consumption areas. This is particularly important in countries, like Uganda, where waste disposal is largely uncontrolled (e.g., large quantities of waste are deposited in water channels with far reaching effects on human and ecosystem health). Further reduction of PHL can be achieved through processing of bananas into semi-elaborated (e.g., banana flour) or elaborated products (e.g., convenience food ready for cooking or direct consumption). This requires investment in processing technologies and equipment, for example, in the framework of public-private partnerships.

The principal determinants for PHL at farm level were sex of household head, household size, education, monthly production, and proportion of land under banana. At the retail level, they included sex of the vendor, participation in traders' groups, source of bananas, and information shared with suppliers. Complementary interventions targeting producers need to focus on increasing farmer mobility (particularly of female headed households) to access bulk markets, farmer organization, and infrastructural improvements. Similarly, interventions at retail level can contribute to enhanced organization of traders and use of modern information and communication technologies for improved linkages with the sourcing areas and tracing of the produce along the value chain.

There is a need to sensitize key value chain stakeholders on PHL and their economic implications, and to involve them in the co-creation of strategies that are aimed at minimizing such losses. The pay-off of viable, co-designed strategies will come in the form of increased food security, particularly in areas where cooking banana is a staple, and reduced pressure on natural resources as less farmland and inputs are needed. Finally, reduced PHL imply higher value chain efficiency, and, consequently, lower costs that can translate into higher trader margins and lower consumer prices, making banana production more sustainable altogether.

Author Contributions: E.M.K., S.A., K.N., D.S. and D.N. conceived and designed the study. E.M.K. and D.N. developed the data collection tools. E.M.K., S.O. and S.A. participated in field research. S.O., E.M.K. and D.N. analyzed and interpreted the data. All authors participated in writing, reviewing and editing the article.

Funding: This research was funded by the European Union with technical support by the International Fund for Agricultural Development (IFAD) through the 'Expanding Utilization of Roots, Tubers and Bananas and Reducing their Postharvest Losses' (RTB-ENDURE), grant number 2000000488.

Acknowledgments: We appreciate the support of all value chain actors who participated in the survey and the enumerators who collected the data used for this paper. This research was undertaken as part of the CGIAR Research Program on Roots, Tubers and Bananas (RTB).

Conflicts of Interest: The authors declare no conflict of interest. 


\section{Appendix}

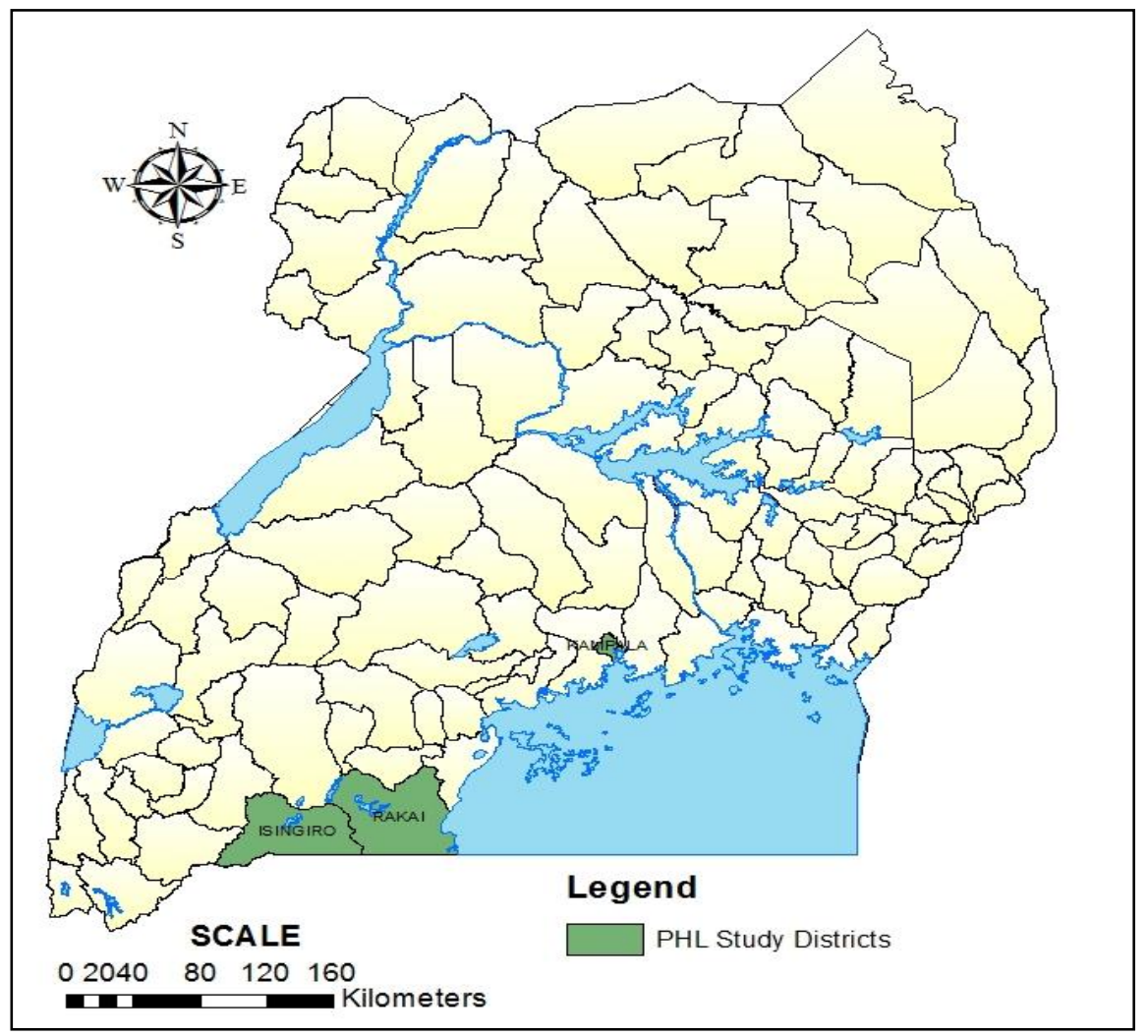

Figure A1. A Map of Uganda Showing the PHL Study Areas. Source: Authors Using Arc GIS.

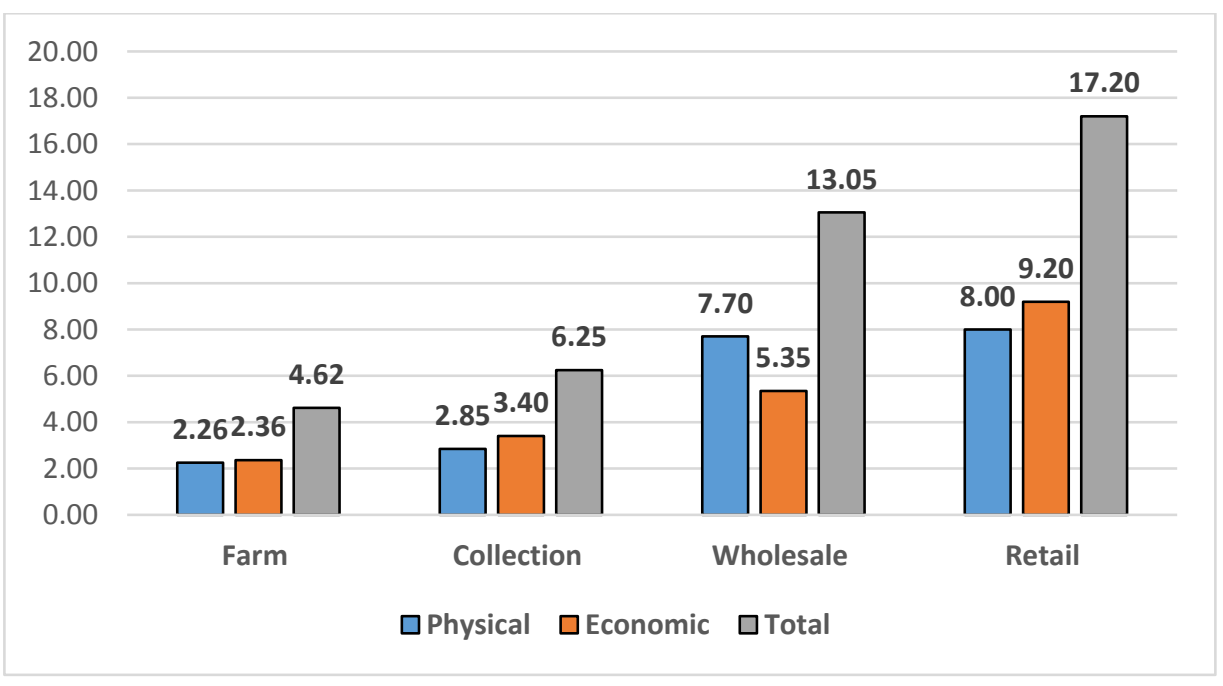

Figure A2. Unweighted physical and economic Losses along the value chain. Source: Authors.

\section{References and Notes}

1. Foresight. The Future of Food and Farming: Challenges and Choices for Global Sustainability; Government for Science: London, UK, 2011.

2. World Bank. Missing Food: The Case of Postharvest Losses in Sub Saharan Africa; World Bank: Washington, DC, USA, 2011. 
3. Food and Agriculture Organization of the United Nations. Global Food Losses and Food Waste-Extent, Causes and Prevention; Food and Agriculture Organization of the United Nations: Rome, Italy, 2011.

4. Affognon, H.; Mutungi, C.; Sanginga, P.; Borgemeister, C. Unpacking Postharvest Losses in Sub-Saharan Africa: A Meta-Analysis. World Dev. 2015, 66, 49-68. [CrossRef]

5. Buzby, J.C.; Hyman, J. Total and per capita value of food loss in the United States. Food Policy 2012, 37, 561-570. [CrossRef]

6. Beretta, C.; Stoessel, F.; Baier, U.; Hellweg, S. Quantifying food losses and the potential for reduction in Switzerland. Waste Manag. 2013, 33, 764-773. [CrossRef] [PubMed]

7. Pedrick, C. Going to Waste-Missed Opportunities in the Battle to Improve Food Security; CTA Policy Brief; CTA: Brussels, Belgium, 2012.

8. Food and Agriculture Organization of the United Nations. How to Feed the World in 2050; Food and Agriculture Organization of the United Nations: Rome, Italy, 2009; Volume 2050.

9. NPA. Republic of Uganda: Second National Development Plan 2015/16; NPA: Aarau, Switzerland, 2015; Volume 20.

10. Food and Agriculture Organization of the United Nations. Food Losses and Waste in the Context of Sustainable Food Systems; Food and Agriculture Organization of the United Nations: Rome, Italy, 2014.

11. Lescot, T. Genetic diversity of the banana. FruiTrop 2015, 231, 98-102.

12. Fiedler, J.L.; Kikulwe, E.M.; Birol, E. An Ex Ante Analysis of the Impact and Cost-Effectiveness of Biofortified High-Provitamin A and High-Iron Banana in Uganda; IFPRI Discussion Paper, Report No. 01277; Poverty, Health and Nutrition Division: Washington, DC, USA, 2013.

13. Kilimo-Trust. Banana Value Chain(s) in East Africa: Consumption, Productivity and Challenges; Kilimo-Trust: Kampala, Uganda, 2012.

14. Kabahenda, M.; Kapiriri, M. Analysing the Agricultural Science and Technology Innovation Systems: A Case Study of the Banana Sub-Sector in Uganda Résumé; RUFORUM: Kampala, Uganda, 2010; pp. 1691-1697.

15. Haggblade, S.; Dewina, R. Staple food prices in Uganda. In Proceedings of the COMESA Policy Seminar on "Variation in Staple Food Prices: Causes, Consequence, and Policy Options", Maputo, Mozambique, 25-26 January 2010.

16. Gebre-Mariam, S. Banana Production and Utilization in Ethiopia; Ethiopian Agricultural Research Organisation: Addis Ababa, Ethiopia, 1999.

17. Kaminski, J.; Christiansen, L. Post-Harvest Loss in Sub-Saharan Africa What Do Farmers Say? World Bank: Washington, DC, USA, 2014.

18. Kitinoja, L.; AlHassan, H.Y. Identification of Appropriate Postharvest Technologies for Small Scale Horticultural Farmers and Marketers in Sub-Saharan Africa and South Asia-Part 1. Postharvest Losses and Quality Assessments. Available online: http:/ / ucce.ucdavis.edu/files/datastore/234-2429.pdf (accessed on 2 July 2018).

19. Adewumi, M.O.; Ayinde, O.E.; Falana, O.I.; Olatunji, G.B. Analysis of Post-Harvest Losses among Plantain/Banana Marketers in Lagos State, Nigeria. Niger. J. Agric. Food Environ. 2009, 5, 35-38.

20. Mebratie, M.A.; Haji, J.; Woldetsadik, K.; Ayalew, A. Determinants of Postharvest Banana Loss in the Marketing Chain of Central Ethiopia. Food Sci. Qual. Manag. 2015, 37, 52-63.

21. TRIAS. Banana (Matooke): Sub Sector Analysis Report; TRIAS: Kampala, Uganda, 2012.

22. De Lucia, M.; Assennato, D. Agricultural Engineering in Development. Postharvest Operations and Management of Food Grains; Food and Agriculture Organization of the United Nations: Rome, Italy, 1994.

23. UBOS \& MAAIF. Uganda Census of Agriculture Crop Area and Production Report. 2010, Volume 4. Available online: www.ubos.org (accessed on 15 July 2017).

24. Naziri, D.; Quaye, W.; Siwoku, B.; Wanlapatit, S.; Viet, T.; Bennett, B. The diversity of postharvest losses in cassava value chains in selected developing countries. J. Agric. Rural Dev. Trop. Subtrop. 2014, 115, 111-123.

25. Basavaraja, H.; Mahajanashetti, S.B.; Udagatti, N.C. Economic Analysis of Post-harvest Losses in Food Grains in India: A Case Study of Karnataka. Agric. Econ. Res. Rev. 2007, 20, 117-126.

26. Tobin, J. Estimation of Relationships for Limited Dependent Variables James Tobin. Econometrica 1958, 26, 24-36. [CrossRef]

27. Beaman, L.; Dillon, A. Do household de fi nitions matter in survey design? Results from a randomized survey experiment in Mali. J. Dev. Econ. 2012, 98, 124-135. [CrossRef] 
28. Wanjari, V.; Ledaniya, M. Marketing of bananas in selected districts of India. Trop. Res. Agric. Ext. 2004, 7 , 126-133.

29. Alliance for a Green Revolution in Africa. Estabslishing the Status of Post-Harvest Losses and Storage for Major Staple Crops in Eleven African Countries (Phase II). Available online: http:/ /agra.org/test/wp-content/uploads/2016/04/establishing-the-status-of-postharvest-lossesand-storage-for-major-staple-crops-2014.pdf (accessed on 2 July 2018).

30. Aulakh, J.; Regmi, A.; Fulton, J.; Alexander, C. Estimating Post-Harvest Food losses: Developing a Consistent Global Estimation Framework; Agricultural and Applied Economics Association: Washington, DC, USA, 2013.

31. Wooldridge, J.M. Econometric Analysis of Cross Section and Panel Data Second Edition; MIT Press: Cambridge, MA, USA, 2002.

32. Jost, C.; Kyazze, F.; Naab, J.; Neelormi, S.; Kinyangi, J.; Zougmoré, R.; Aggarwal, P.; Bhatta, G.; Chaudhury, M.; Tapio-Bistrom, M.L.; et al. Understanding gender dimensions of agriculture and climate change in smallholder farming communities. Clim. Dev. 2016, 8, 133-144. [CrossRef]

33. Mayanja, S.; Mudege, N.N.; Naziri, D. Gender Situational Analysis of the Banana Value Chain in Western Uganda and Strategies for Gender Equity in Postharvest Innovations; CGIAR Roots, Tubers and Bananas (RTB): Lima, Peru, 2016.

34. Aidoo, R.; Danfoku, R.A.; Mensah, J.O. Determinants of postharvest losses in tomato production in the Offinso North district of Ghana. J. Dev. Agric. Econ. 2014, 6, 338-344.

(C) 2018 by the authors. Licensee MDPI, Basel, Switzerland. This article is an open access article distributed under the terms and conditions of the Creative Commons Attribution (CC BY) license (http://creativecommons.org/licenses/by/4.0/). 